\title{
Hearing Profile in Patients with Dilated and Hypertrophic Cardiomyopathies
}

\author{
Gehan Abd El-Rahman El-Zarea1, Yasser Elsayed Mohamed Hassan², Ahmed Mohamed Ahmed Mahmoud
}

${ }^{1}$ Professor of Audiology, ENT Department, Faculty of Medicine, Al-Azhar University

${ }^{2}$ Assistant Professor of Cardiology, Cardiology Department, Faculty of Medicine, Al-Azhar University

${ }^{3}$ Lecturer of Audiology, ENT Department, Faculty of Medicine, Al-Azhar University

\section{Type of article: Original}

\begin{abstract}
Introduction: Cardiomyopathy may cause disruptions in the micro-vascular system of the stria vascularis in the cochlea, and, subsequently, may result in cochlear degeneration. Degeneration in the stria vascularis affects the physical and chemical processes in the organ of Corti, thereby causing a possible hearing impairment. The objective of this study was to assess the hearing profiles of patients with dilated and hypertrophic cardiomyopathies to determine the relationship between the degree of hearing loss and the degree and duration of the disease and to compare the dilated and hypertrophic cardiomyopathies as regards hearing profile.

Methods: In this case control study, we studied 21 patients (cases/study group/group 1) and 15 healthy individuals (controls/group 2). Six patients (group 1a) had hypertrophic cardiomyopathy (HCM), and 15 patients (group $1 \mathrm{~b}$ ) had dilated cardiomyopathy (DCM). The data were analyzed using the t-test, chi-squared test, Kruskal-Wallis test, and the Multiple Mann-Whitney test.

Results: The results of this study showed that $80 \%$ of those patients with DCM (group 1b) had bilateral sensorineural hearing loss (SNHL), and $100 \%$ of the patients with HCM (group 1a) had mild to severe bilateral sloping SNHL. Distortion Product Otoacoustic Emissions (DPOAEs) were present in 14\% of the study group and in $100 \%$ of the control group. The results of the measurements of auditory brainstem response (ABR) showed that $50 \%$ of the study group had abnormal latencies compared to the control group, and there was no correlation between the duration of the disease and the degree of hearing loss or DPOAE. Fifty percent of the patients with HCM and $35 \%$ of the patients with DCM had positive family histories of similar conditions, and $35 \%$ of those with HCM had a positive family history of sudden death.

Conclusion: The results of this study suggested that the link between heart disease and hearing loss and early identification of hearing loss in patients with cardiomyopathy may reduce morbidity since hearing deficits sometimes precede heart disease.

Keywords: cardiomyopathy, hearing profile, dilated cardiomyopathy, hypertrophic cardiomyopathy
\end{abstract}

\section{Introduction}

Hearing loss is the most common sensory defect in developed countries (1). Hearing impairment in adults is defined as a permanent, unaided hearing threshold level of $25 \mathrm{~dB}$ or greater in the better ear (2). In 1995, the World Health Organization estimated that 120 million individuals were living with hearing impairments and that 78 million of them were in third world countries (3). The recent literature has indicated that the number of individuals with hearing impairments is likely to increase and that the age of onset is likely to decrease (4). The world report on disability (5) indicated that 278 million people worldwide have moderate to profound hearing impairments. In 2011, the global prevalence of hearing loss was estimated to be $9.8 \%$ in females and $12.2 \%$ in males (6). In Egypt, Hamid et al. (7) found that hearing loss in children up to the age of 14 was $13.8 \%$ of the 1,600 who were tested. Sensorineural hearing loss results from a defect in the cochlea and/or the auditory division of the vestibulocochlear nerve that causes decreased ability to perceive sounds. Unfortunately, hearing loss caused by such a defect usually is

\section{Corresponding author:}

Assistant Professor Dr. Yasser Elsayed Mohamed Hassan, Cardiology Department, Faculty of Medicine, Al-Azhar University, Cairo, Egypt. E-mail: yasserelsayed97@yahoo.com

Received: September 13, 2015, Accepted: December 13, 2015, Published: February 2016

iThenticate screening: October 13, 2015, English editing: January 28, 2016, Quality control: February 02, 2016 (C) 2016 The Authors. This is an open access article under the terms of the Creative Commons Attribution-NonCommercialNoDerivs License, which permits use and distribution in any medium, provided the original work is properly cited, the use is non-commercial and no modifications or adaptations are made. 
irreversible. The hearing losses tend to be distributed unevenly, and the greater losses seem to be associated with the higher frequencies. There are many possible causes of sensorineural hearing loss, including congenital malformation of the inner ear, viral infections, trauma, intense noise, ototoxic drugs (e.g., cisplatin, salicylates, and loop diuretics), fractures of the temporal bone, meningitis, Meniere's disease, cochlear otosclerosis, presbycusis, and genetic predisposition. These possible causes can have adverse effects alone, in combination, or in association with environmental factors (8).

The heart performs the crucial function of providing a supply of blood to all the parts of the body. Therefore, any dysfunction or abnormality of the heart is likely to affect the entire body (9). These effects include fatigue, reduced mobility in the limbs, and some degree of failure in the functioning of major organs, such as the liver and lungs. There also is evidence of some degree of disruption in the functioning of other organs, such as the auditory system (10). The cochlea are situated in the inner ear and convert sound vibrations into action potentials that are transmitted to the auditory cortex for interpretation. Blood is supplied to the cochlea by the labyrinthine artery, which arises from the meatal loop of the middle cerebral artery or a branch from the basilar artery, which penetrates into the internal acoustic meatus. Both spiral and radial arteries are present within the cochlea (11). The stria vascularis arteries in the cochlea have a large capillary blood flow. A decrease in the blood supply to the cochlea as a result of cardiovascular disease may result in cochlear degeneration and will disrupt the physical and chemical processes in the cochlea (12). This, in turn, may lead to hearing impairment (13). The cochlea are tonotopically organized, as the base of the cochlea identifies and transmits high-frequency stimuli, and the apex of the cochlea do the same for lowfrequency stimuli (11). This allows high sensitivity and frequency selectivity in the cochlea. The comparatively limited blood flow to the apex makes it vulnerable to degeneration, which can present as a possible low-frequency sensorineural hearing loss (14). Hearing loss as a result of cochlear hypoxia was confirmed in a recent study (15). This finding was supported by other studies that reported the absence or significantly reduced distortion product otoacoustic emissions following an ischemic injury to the cochlea. Diseases of the myocardium associated with cardiac dysfunction are referred to as cardiomyopathies, and they range from lifelong symptomless forms to major health problems that can include progressive heart failure, arrhythmia, thromboembolism, and sudden cardiac death. Cardiomyopathies are classified based on their morphological characteristics either as hypertrophic cardiomyopathies (HCMs) or dilated cardiomyopathies (DCMs) (16). Typically, HCMs are characterized by left ventricular hypertrophy, diastolic dysfunction, and hypercontractility, and they often are associated with disabling symptoms, arrhythmias, and sudden death. FHC shows both non-allelic and allelic genetic heterogeneity, and nonsarcomeric genes also may be responsible. Non-sarcomeric causes of FHC have not been thoroughly characterized, and they may be associated with distinct phenotypes or combinations of phenotypes (17). DCM is characterized as a disease of the heart muscle that is characterized by ventricular dilatation and impaired heart contraction. This disease is known to be heterogeneous from both clinical and genetic perspectives (18). Several studies have indicated that 25 to $30 \%$ of DCM is familial (19). DCM and sensorineural hearing loss (SNHL) are prevalent disorders that can occur alone or as components of complex, multi-system syndromes. However, there has been no prior identification of any isolated co-inheritance of these phenotypes (20). Similarly, incidents of hereditary sensorineural hearing loss have a significant degree of non-allelic and allelic genetic heterogeneity, which can be dominant, recessive, Xlinked, or mitochondrial. Sensorineural hearing loss that is known to be hereditary is classified based on the mode of inheritance and the presence or absence of clinically-detectable, extra-auditory manifestations, i.e., syndromic deafness or non-syndromic deafness, respectively (17). Therefore, it is important to determine the hearing profiles of patients with dilated and hypertrophic cardiomyopathies.

\section{Material and Methods}

\subsection{Study design and setting}

The subjects of this case-control study were divided into two groups. Group 1 was the study group, and Group 2 was the control group. Twenty-one patients (age range of 15-55 years) were referred from the Cardiology Clinic to the Audiology Unit at Al Hussein Hospital and divided into two sub-groups. Group 1a had six patients with hypertrophic cardiomyopathy (HCM), and group $1 \mathrm{~b}$ had 15 patients with dilated cardiomyopathy (DCM). The control group consisted of 15 normal, healthy volunteers. They were selected from the relatives who accompanied the patients.

\subsection{Selection criteria (cases)}

2.2.1. Inclusion criteria

All patients were chosen according to the tenets of the European Society of Cardiology. These were 1) HCM was defined by a wall thickness $\geqslant 15 \mathrm{~mm}$ in one or more LV myocardial segments as measured by echocardiogram, 2) 
DCM was defined by left ventricular (LV) ejection fraction $<45 \%$ or fractional shortening $<25 \%$ diagnosed by echo cardiogram, and LV end diastolic diameter $>117 \%$ of the predicted value corrected for age and body surface area. .

\subsubsection{Exclusion criteria}

The exclusion criteria were having a past history of ear problems and the observance of any ear, nose, or throat abnormalities in the clinical examinations.

\subsection{Selection criteria (controls)}

The controls were chosen according to the following criteria: matching for age and gender distribution with those for the study group; no history of ear problems, hearing loss, or cardiac problems; normal tympanic membrane as regards color, translucency, cone of light, and mobility on Siegel' s examination; pure tone thresholds within the normal range ( $\leqslant 25 \mathrm{~dB}$ in the $250-8000 \mathrm{HZ}$ range); and normal middle ear functions as shown by immittancemetry.

\subsection{Equipment}

The equipment used in this study included Resting conventional Echo Doppler study, two-channel diagnostic audiometer (Interacoustics, model AC40), Immittancemeter (Interacoustics, model AZ26), Otoacoustic Emisson Analyzer Madsen model (Celesta 503), evoked potential audiometer model (Nicolet Compact four), and soundtreated room (locally made) according to the international specifications of sound-treated rooms.

\subsection{Methods}

2.5.1. History, Medical examination, and Laboratory investigation

Full histories were taken for the subjects of the study and the members of the control groups with emphasis on hearing problems, cardiac manifestations and duration of the disease, symptoms of heart failure, irregular beats, and family history of similar conditions and sudden death. The laboratory investigation included complete blood count (CBC), renal function tests, and liver function test.

2.5.2. Echocardiographic imaging

Echocardiograms were performed with the patients breathing quietly and lying in the left, lateral position. Four acoustic views (parasternal long axis, parasternal short axis, apical four chamber, and apical two chamber) were obtained to assess the systolic LV function by measuring the end diastolic and end systolic diameters of the left ventricle using M-mode recording under the guidance of 2D Echocardiography according to the recommendation of the American Society of Echocardiography. The end diastole at the onset of QRS complex and the end systole at the point of maximum upward motion of LV posterior wall endocardium. These measurements should be made from leasing edge to leading edge. The M-mode LV dimensions were used to estimate the ventricular volume and the ejection fraction, if desired, most simply by merely cubing the value (D) 3 or using the Teicholz Technique and calculating the ejection fraction (EF).

2.5.3. Audiological evaluation

The basic audiological evaluations consisted of pure tone audiometry, speech audiometery, Immittancemetry, and Acoustic reflex as follows:

1) Pure tone audiometry: We determined air conduction hearing threshold levels for octave frequencies between $250-8000 \mathrm{~Hz}$ and bone conduction thresholds for frequencies between 500-4000 Hz. The thresholds were taken as the faintest sound that the patients responded to $50 \%$ of the time. Masking was used whenever indicated.

2) Speech audiometery: This evaluation included the speech reception threshold (SRT) using Arabic spondee words (21) and word discrimination scores (WDS) using phonetically-balanced Arabic words (22).

3) Immittancemetry and Acoustic reflex: In this section, tympanometry was done at various pressures, ranging from +200 to $-400 \mathrm{~mm} \mathrm{H} 2 \mathrm{O}$, to evaluate the pressure in the middle ear and its compliance. Also, acoustic reflex thresholds were elicited both ipsilaterally and contralaterally using pure tones of 500, 1000, 2000, and $4000 \mathrm{~Hz}$.

2.5.4. Acoustic distortion product gram recording:

Stimulus generation: The stimulus consisted of two equal, pure-tone signals at two different frequencies, i.e., fl and $\mathrm{f} 2(\mathrm{f} 1<\mathrm{f} 2)$, that were generated simultaneously by the equipment with an $\mathrm{f} 2 / \mathrm{f} 1$ ratio of 1.22 . The two primaries was chosen so that their geometric mean was at the same test frequency used to obtain hearing thresholds and at a primary level of $70 \mathrm{~dB}$ SPL. The two signals were conducted separately in two transducers and, then, by silicon rubber tube to the probe housing. The two signals were conducted entirely independently and then acoustically mixed only in the external ear canal. 


\subsection{Statistical Analysis:}

The following statistical tests and parameters were used: mean \pm standard deviation (SD), the student's t-test, and the chi-squared test.

\section{Results}

In the study (case) group (group 1), there were 21 patients (group 1a and group 1b). Group 1a included six patients (five males and one female) who had hypertrophic cardiomyopathy. Their ages ranged from 34 to 54 (43 \pm 8.7 ). Group $1 \mathrm{~b}$ (dilated cardiomyopathy) included 15 patients (nine males and six females). Their ages ranged from 15-55 $(45.3 \pm 15.1)$. There was no statistically significant difference between the ages of the males and females $(p>0.05)$. Both ears of all subjects with cardiomyopathy were evaluated, so the total number of ears was 42 . Basic audiologiacl evaluation was done for all subjects included in this study, and the results indicated that all cases had bilateral, typeA tympanograms, reflecting normal middle ear pressure except three ears had type-C tympanograms due to Eustachian tube dysfunction due to common colds. The results of speech audiometry and acoustic reflex testing were consistent with cochlear hearing loss. The affected adults had SNHL that affected frequencies to varying degrees with a variety of audiometric configurations, but the two youngest subjects had SNHL that affected only the low and middle frequencies. In the control group (group 2), there were 15 healthy individuals (seven males and eight females). Their ages ranged from 15 to $55(41.1 \pm 13.4)$. All controls had normal bilateral peripheral hearing in the frequency range of 250-8000 $\mathrm{Hz}$. They all had bilateral type-A tympanograms. In this study, three patients with HCM had positive family histories of similar conditions, and two of these patients had positive family histories of sudden death. In the group of dilated cardiomyopathy, five patients in the same family had the disease. Table 1 shows the age and gender distribution among the groups that were studied. The pure tone threshold of the study group vs. control groups showed that the means of the hearing thresholds were significantly higher in both ears for all frequencies in patients with cardiomyopathy than in the controls. By the post hoc test, the significant difference was seen between group $1 \mathrm{a}$ vs. group 2 , group $1 \mathrm{~b}$ vs. group 2 , and group 2 vs. group $1 \mathrm{a}$, group $1 \mathrm{~b}$. Twelve of 15 patients with DCM had bilateral SNHL, which ranged from mild to severe and that affected all frequencies, especially the high frequencies, resulting in a down-sloping audiometric configuration. Three patients had normal hearing sensitivity. In this study, six patients $(100 \%)$ was diagnosed with hypertrophic cardiomyopathy, and they also had bilateral mild-to-severe sloping SNHL. The SRTs between the study group and the control group were found to be very-highly significant statistically. By the post hoc test, the significant difference was seen between group $1 \mathrm{a}$ vs. group 2 , group $1 \mathrm{~b}$ vs. group 2 , and group 2 vs. group $1 \mathrm{a}$, group $1 \mathrm{~b}$. Comparing speech discrimination between the control and study group indicated that there were no significant differences between the two groups ( $p>$ 0.05) (Table 2).

Table 1. Age and gender distribution among the studied groups

\begin{tabular}{|l|l|l|l|l|l|}
\hline \multirow{2}{*}{ Variables } & \multicolumn{2}{l|}{ Cases } & Controls & \multirow{2}{*}{ p-value } \\
\cline { 3 - 6 } & HCM & DCM & & \\
\hline \multicolumn{2}{|l|}{ Age $($ mean \pm SD) } & $43 \pm 8.7$ & $45.3 \pm 15.1$ & $41.1 \pm 13.4$ & 0.7 \\
\hline \multirow{2}{*}{ Gender, n $(\%)$} & Male & $1(16.7 \%)$ & $9(60 \%)$ & $7(46.7 \%)$ & 0.07 \\
\cline { 2 - 5 } & Female & $5(83.3 \%)$ & $6(40 \%)$ & $8(53.3 \%)$ & \\
\hline
\end{tabular}

Table 2. Speech discrimination among the studied groups

\begin{tabular}{|l|l|l|}
\hline \multirow{2}{*}{ Groups } & \multicolumn{2}{|l|}{ Speech discrimination } \\
\cline { 2 - 3 } & Excellent & Good \\
\hline Group 1a, n (\%) & $5(83.3 \%)$ & $1(16.7 \%)$ \\
\hline Group 1b, n (\%) & $14(93.3 \%)$ & $1(6.7 \%)$ \\
\hline Group 2, n (\%) & $30(100 \%)$ & $0(0 \%)$ \\
\hline $\mathrm{X}^{2}$ & 4.9 & \\
\hline p-value & 0.09 & \\
\hline
\end{tabular}

Comparing the amplitude of the DPOAE of the frequencies in the range of $500-8000 \mathrm{~Hz}$ by using the KruskalWallis test, we found no significant differences, except at 2000 and $4000 \mathrm{~Hz}$, and, by using multiple Mann-Whitney tests, there was no significant difference between the groups, with the exception that there were significant differences between group $1 \mathrm{a}$ vs. group 2 , group $1 \mathrm{~b}$ vs. group 2, group 2 vs. group 1a and group $1 \mathrm{~b}$ at $2000 \mathrm{~Hz}$. At $4000 \mathrm{~Hz}$, there was a difference between group $1 \mathrm{~b}$ vs. group 2. DPOAE was present in six ears with mild to moderate SNHL and 30 ears of the control group (Table 3). Comparing the signal-to-noise ratio of DPOAE by using 
the Kruskal-Wallis test in the frequency range of 500-8000 Hz indicated that there was no significant difference, except at $500 \mathrm{~Hz}$. By using the post hoc test, there was no significant difference between the groups, except at 500 $\mathrm{Hz}$ (group 1a vs. group 2), at $2000 \mathrm{~Hz}$ (group 1a vs. group 2), and at $4000 \mathrm{~Hz}$ (group 1b vs. group 2) (Table 4). Comparing the absolute latencies of ABR waves I, III, and V between the control and study groups revealed no significant difference between the two groups in waves I and III, but there was a highly-significant difference in wave V. By using the post hoc test, we found no significant difference between the two groups in waves I, III, and V in group 1a, but there was a significant difference between group $1 \mathrm{~b}$ vs. group 2 in wave V. The results of ABR measurement showed that 50\% in the study group had abnormal latency compared to the control group (Table 5). Comparing the mean of the inter-peak latencies and wave $\mathrm{V}$ of high repetition rate stimulation between the study and control groups indicated that there was no significant difference between the groups in (I-III and III-V), but there was a significant difference in $(\mathrm{I}-\mathrm{V})$ and $\mathrm{V}^{\prime}<0.05$. By the post hoc test, there was a significant difference between group Ib vs. group 2 in I-V. Also, there were significant differences between group 1a vs. group 2, group 1b vs. group 2, and group 2 vs. group $1 \mathrm{a}$ and group $1 \mathrm{~b}$ in $\mathrm{V}^{\prime}$. Regarding comparing the degree of hearing loss with the duration of the disease, the results of this study did not show any significant difference. Also, no statistically significant difference was present between the duration of disease and the absolute latencies of the ABR waves (correlation co-efficient was weak), and there was no significant difference between the duration of the disease and inter-peak latencies of the ABR waves (correlation co-efficient was weak).

Table 3. Mean and SD of amplitude of DPOAE among study and control groups

\begin{tabular}{|c|c|c|c|c|c|c|c|c|c|}
\hline \multirow[t]{2}{*}{ Groups } & \multicolumn{9}{|c|}{ Amplitude of DPOAE, Mean(SD) } \\
\hline & 500 & 750 & $1 \mathrm{~K}$ & $1.5 \mathrm{~K}$ & $2 \mathrm{~K}$ & $3 \mathrm{~K}$ & $4 \mathrm{~K}$ & $6 \mathrm{~K}$ & $8 \mathrm{~K}$ \\
\hline Group 1a & $1.3(2.7)$ & $3.7(3.1)$ & $6.5(1.4)$ & $3.8(5.6)$ & $1.3(3.1)$ & $6.2(2.1)$ & $4.7(5)$ & $\begin{array}{l}11.8 \\
(4.2)\end{array}$ & $1.3(3.1)$ \\
\hline Group 1b & $1.4(13)$ & $4.1(3.5)$ & $6.4(6)$ & $5.4(6.8)$ & $1.2(2.1)$ & $6.7(3.9)$ & $3.6(4.5)$ & $10.3(8)$ & $5.1(7.6)$ \\
\hline Group 2 & $1.6(2.4)$ & $5.6(4.4)$ & $8.6(5.1)$ & $8.6(5.1)$ & $5.6(5.4)$ & $8(4.1)$ & $7.7(5.5)$ & $\begin{array}{l}14.4 \\
(7.3)\end{array}$ & $5.5(5.7)$ \\
\hline $\begin{array}{l}\text { Kruskal- } \\
\text { Wallis test }\end{array}$ & 1.7 & 3.1 & 2.4 & 6.3 & 13.3 & 4.3 & 6.9 & 6.6 & 6.4 \\
\hline Sig. & 0.4 & 0.2 & 0.3 & 0.06 & 0.001 & 0.1 & 0.03 & 0.05 & 0.05 \\
\hline
\end{tabular}

Table 4. Comparison between $\mathrm{S} / \mathrm{N}$ ratio of DPOAE among study and control groups

\begin{tabular}{|l|l|l|l|l|l|l|l|l|l|l|}
\hline \multirow{2}{*}{ Groups } & \multicolumn{9}{|l|}{ Amplitude of DPOAE, Mean(SD) } \\
\cline { 2 - 11 } & 500 & 750 & $1 \mathrm{~K}$ & $1.5 \mathrm{~K}$ & $2 \mathrm{~K}$ & $3 \mathrm{~K}$ & $4 \mathrm{~K}$ & $6 \mathrm{~K}$ & $8 \mathrm{~K}$ \\
\hline Group 1a & $1.7(3.4)$ & $6.7(6.2)$ & $\begin{array}{l}11.5 \\
(6.1)\end{array}$ & $13(10.5)$ & $10(8.2)$ & $\begin{array}{l}22.3 \\
(5.6)\end{array}$ & $\begin{array}{l}17.2 \\
(9.7)\end{array}$ & $8.8(4.5)$ & $2.3(6.2)$ \\
\hline Group 1b & $6.3(5.9)$ & $7.6(7.2)$ & $\begin{array}{l}10.9 \\
(7.6)\end{array}$ & $\begin{array}{l}13.3 \\
(9.7)\end{array}$ & $\begin{array}{l}14.3 \\
(5.3)\end{array}$ & $24(6)$ & $\begin{array}{l}15.2 \\
(8.3)\end{array}$ & $5.7(8.6)$ & $\begin{array}{l}8.1 \\
(10.7)\end{array}$ \\
\hline Group 2 & $6.3(5.5)$ & $\begin{array}{l}11.6 \\
(6.4)\end{array}$ & $14(5.4)$ & $\begin{array}{l}16.5 \\
(5.3)\end{array}$ & $\begin{array}{l}15.4 \\
(6.2)\end{array}$ & $20(7.7)$ & $\begin{array}{l}17.5 \\
(5.9)\end{array}$ & $\begin{array}{l}11.1 \\
(8.3)\end{array}$ & $9.1(8.9)$ \\
\hline $\begin{array}{l}\text { Kruskal- } \\
\text { Wallis test }\end{array}$ & 7.3 & 6.2 & 2.5 & 1.4 & 3.8 & 5 & 2.2 & 5.3 & 5.2 \\
\hline Sig. & 0.03 & 0.06 & 0.3 & 0.5 & 0.1 & 0.1 & 0.3 & 0.07 & 0.07 \\
\hline
\end{tabular}

Table 5. Comparison of absolute latencies of ABR waves in the study and control groups

\begin{tabular}{|l|l|l|l|}
\hline Groups & I $($ Mean \pm SD) & III $($ Mean \pm SD) & V $($ Mean \pm SD) \\
\hline Group Ia & $1.7 \pm 0.3$ & $3.7 \pm 0.3$ & $5.7 \pm 0.2$ \\
\hline Group Ib & $1.6 \pm 0.2$ & $3.8 \pm 0.2$ & $5.8 \pm 0.2$ \\
\hline Group II & $1.6 \pm 0.1$ & $3.7 \pm 0.1$ & $5.6 \pm 0.1$ \\
\hline F & 0.9 & 1.8 & 5.2 \\
\hline Sig & 0.4 & 0.2 & 0.007 \\
\hline
\end{tabular}

\section{Discussion}

The brain and other neural tissues (e.g., cochlea) are particularly sensitive to the flow of blood (23). In Africa, hypertension is the most common cause of myocardial disease, and it is followed by cardiomyopathy. For more than 
60 years, the classifications of cardiomyopathy have been being revised. Information on structural and functional abnormalities, organ involvement, genetic etiology, and the severity of disease is incorporated in the new MOGE(s) classification system (24). Arbustini et al. (25) presented new notations in the MOGE(s) system to address the five attributes of cardiomyopathies, i.e., (M) the structural and functional abnormality (myopathy), (O) the extent of organ involvement, $(\mathrm{G})$ whether the disease is a genetic or non-genetic condition, (E) the nature of the molecular genetic defect or other etiology, if known, and and (S) the optional inclusion of the stage of heart failure and the degree of effort intolerance (S). We designed the current study to evaluate the hearing profiles of patients with cardiomyopathies. Thirty-six subjects participated in this study, and their age range was 15-55. The study group consisted of 21 patients, 15 with dilated cardiomyopathy and 6 with only the hypertrophic type. The basic audiological evaluations remained the keystone of the audiological diagnosis to define the degree, type, and configuration of hearing loss (26). The configuration of the audiogram may provide information that can be used to determine the cause of SNHL (27). Eighty percent of 15 patients with DCM had bilateral SNHL that ranged from mild to severe, and it affected all frequencies, with the high frequencies being affected the most, resulting in a downsloping audiometric configuration. Twenty percent (three patients) had normal hearing sensitivity. Word recognition scores were within the expected ranges for the degree of hearing loss. Schonberger et al. (20) reported that many members of two families were affected by sensorineural hearing loss that occurred mostly in early adulthood. Their hearing loss occurred before the appearance of dilated cardiomyopathy (DCM), which usually occurs when people are 40 or older. It was determined that DCM and SNHL were inherited as autosomal dominant and linked to chromosome 6q23 to 24. Schonberger et al. (20) considered a candidate gene to be the gene-encoding epicardin, which is a transcription factor that is expressed in the myocardium and in the cochlea, but they did not identify a specific mutation. In a later study, Schonberger et al. (28) found a deletion in the EYA4 gene, and they found that it occurred in all affected family members but did not occur in any of the 300 control patients. SNHL with DCM could be the result of the mutation of a single protein that has an important biological function in the ears and the heart, which is the case in Jervell and Lange Nielson syndrome. Mutation in the $\mathrm{K}$ channel components are known to cause such disorders, and they delay myocellular repolarization in the heart (29). However, in the ear, such mutations prevent the secretion of $\mathrm{K}$ into the endolymph, which changes the ionic environment that is necessary for the normal functioning of hair cells (30).

In this study, the six patients who were diagnosed with hypertrophic cardiomyopathy had bilateral-mild sloping SNHL to severe sloping SNHL. In the study of Mohiddin et al. (17), 36 subjects with familial hypertrophic cardiomyopathy were examined, and 17 of them had SNHL. Their hearing loss began early in the post-lingual period during their first 10 years of life, after which there was a gradual, steady progression of the disease. It was found that the test results from speech audiometry and acoustic reflex tests were consistent with cochlear hearing loss. It was evident that there was a history of progressive hearing loss that affected several generations in the family, and this was suggestive of autosomal dominant inheritance (17). The two youngest subjects who had SNHL were affected only at the middle and low frequencies. In contrast, the hearing losses of the adults occurred to varying degrees at various frequencies with several audiometric configurations. Mohiddin et al. (17) also evaluated other family members who had SNHL and found ECG and echocardiographic abnormalities. Bilateral low frequency SNHL, which progressed in severity beginning at about age 10, apical left ventricular hypertrophy, and prolonged QT intervals were the most typical phenotypes. Endolymphatic hydrops also could be proposed on the basis of low frequency SNHL due to defects in fluids in the inner ear. They concluded that a possible cardio auditory syndrome may be associated with a dominant mutation in a gene encoding an unconventional myosin VI. Genetic analysis suggested linkage of this cardio auditory syndrome to a region at $6 \mathrm{q} 13$ encompassing the MYO6. More than 400 genetic syndromes that include hearing loss and more than 60 different genetic loci that lead to hearing loss have been identified. Traditionally, these have been categorized as recessive, dominant, or X-linked disorders. Recently, it has become clear that mitochondrial diseases, which comprise another group of genetic diseases, contribute to a large proportion of inherited hearing loss that had been unexplained in the past. Mitochondrial disorders, in addition to strict maternal inheritance, may be inherited in the traditional Mendelian manner. It is also possible that there are sporadic inheritance patterns in which spontaneous DNA mutations occur during oogenesis or early embryogenesis (31). Usually, mitochondrial disorders develop first in tissues that have high metabolic demands, such as nerves and muscles, including the heart muscle. This observation places the complete auditory pathway peripherally from the cochlea and centrally to the brain stem at risk in mitochondrial diseases. This helps to explain the routine findings of hearing loss as part of the initial presentation of mitochondrial disorders (32). Santorelli et al. (33) described maternally-inherited cardiomyopathy and SNHL with mutation in the mitochondrial $t$ RNA gene G8363A. This occurs because tissues with high oxidative metabolism, such as the heart and the cochlea, are particularly vulnerable to impaired mitochondrial function. They concluded that, mitochondrial mutation should 
be considered in the differential diagnosis, particularly when there is evidence of maternal inheritance. The cochlea have been reported to be the site of functional lesions that lead to hearing loss in mitochondrial diseases. In one type of mitochondrial disease, the stria vascularis was considered to be the principle site of the defects (34).

The results of tympanometry always should be viewed in conjunction with pure tone audiometry. Patients with SNHL usually have normal middle ear function. All cases have bilateral type-A tympanograms reflecting normal middle ear pressure, except that three ears had type-C tympanogram due to the common cold, which caused dysfunctions of the Eustachian tubes. In this study, DPOAEs were done as rapid, objective, and non-invasive audiological procedures to study the cochlear function or (outer hair cell function). Since distortion product otoacoustic emissions provide frequency-specific information based on discrete frequency stimuli, they often are compared to audiometric configurations. In individuals with sensorineural hearing loss, distortion product otoacoustic emissions are often eliminated only for the stimulus frequency regions that coincide with the impaired region (35). DPOAEs were present in 14\% (six ears) with mild to moderate SNHL and $100 \%$ of the controls (30 ears). The response amplitudes were reduced markedly in the study group when compared with the DPOAE amplitude recorded from the control group, indicating impaired cochlear function in study group. Background noise is significant higher at low frequencies than at high frequencies. In this study, the results of ABR measurements showed that $50 \%$ had abnormal latency in the study group compared to the control group. There was a statistically significant difference in the absolute latency of the wave V only. This was because, in high-frequency SNHL, the wave travel downs the basilar membrane until it reaches hair cells that are sufficiently intact to provide a synchronous discharge; hence, there is a delay in the waveform. Also, there was a difference in the inter-peak latencies, which was statistically significant only in the I-V interval, which means there was a delay in the whole conduction time. Edmonds et al. (32) reported that $80 \%$ of the group they studied that had mitochondrial disorders had significant hearing dysfunction at the time of evaluation; only $20 \%$ had normal hearing, and 20 of the 35 patients had central (brain stem) defects as documented by a significant delay of the I-V interval in both their RT and LT ears. Five patients among the 35 patients (14\%) had significant asymmetry of the I-V interval in their RT and LT ears. Also, 67\% had abnormal morphologies of the waveforms. They reported that patients with the A1555G mitochondrial DNA mutation exhibited mild, high-frequency, progressive hearing loss with ABR changes. In this study, it also was observed that increasing the click repetition rate caused more prolonged latencies of wave $\mathrm{V}$ in the study group. This means that there was an increase in the conduction time in the auditory nerve and its central connection in the studied groups. Therefore, subtle changes in ABR would appear when subjecting the system to stress using a high repetition rate. No correlation between the duration of the disease and the degree of hearing loss was determined. The correlation coefficient value of $0.13(\mathrm{R}<0.5)$ is very weak. Also, no correlation between the duration of the disease and absolute and inter peak latencies of ABR waves were found. This disagrees with the study of Solkani (36), who found that the duration of cardiovascular disease was influenced significantly for all airconduction thresholds in the right ear, and it was influenced at 250, 500, 1000, and $2000 \mathrm{~Hz}$ in the left ear. In the population we studied, hearing dysfunction had not been recognized earlier in any of the patients. This might be explained by the young age of most of the patients in addition to the presence of cardiac problems, and other manifestations that overshadowed the presence of hearing dysfunctions. Cardiomyopathies either are confined to the heart or they are a part of generalized systemic disorders, and they often lead to progressive heart failure or cardiovascular death (Maron et al., 2006). This necessitates close monitoring and early intervention to reduce the high morbidity and mortality.

\section{Conclusions}

Twelve of 15 patients (80\%) with DCM had bilateral SNHL, and $100 \%$ of patients with hypertrophic cardiomyopathy had mild-to-severe bilateral sloping SNHL. DPOAEs were present in 14\% of the study group and $100 \%$ of the control group. The results of ABR measurement showed that $50 \%$ of the study group had abnormal latencies compared to the control group. Fifty percent of the patients with HCM and 35\% of those with DCM had a positive family history of similar conditions, and 35\% of HCM have family history of sudden death. This study showed that cardiomyopathy disease affects the heart and also may have an adverse impact on the auditory system.

\section{Acknowledgments:}

The authors thank the participants in the study and the staff at Al-Azhar University.

\section{Conflict of Interest:}

There is no conflict of interest to be declared. 


\section{Authors' contributions:}

All authors contributed to this project and article equally. All authors read and approved the final manuscript.

\section{References}

1) Hildbrand $\mathrm{M}$, Gubbus $\mathrm{S}$, Rose $\mathrm{S}$ and Newton $\mathrm{S}$. Advances in molecular and cellular therapies for hearing loss .J of molecular therapy, 2007; $162: 224-36$.

2) World Health Organization. Prevention of blindness and deafness (PBD). Guidelines for Hearing Aids and Services for Developing Countries (2nd ed). 2004; Retrieved April 27, 2010 from http://whqlibdoc.who.int/publications/2004/9241592435_eng.pdf

3) Solarsh G and Hofman K. Developmental disabilities. In D. Jamison, R. Feachem, M. Makgoba, E. Bos, F. Baingana, K. Hofman, et al., Disease andmortality in Sub-Saharan Africa (2nd ed.):125-48; Washington, DC: The World Bank. 2006

4) De Sousa C S, De Castro Junior N, Larsson E. Jand Ching T. H (2009): Risk factors for presbycusis in a socio-economic middle-class sample. Brazilian Journal of Otorhinolaryngology; 75(4): 530-536. doi: 10.1016/S1808-8694(15)30492-4

5) World Health Organization (WH). World report on disability. 2011; Retrieved on May 22,2012 from http://whqlibdoc.who.int/publications/2011/9789240685215_eng.pdf

6) Stevens G, Flaxman S, Brunskill E, Mascarenhas M, Mathers C, Finucane. Global and regional hearing impairment prevalence: An analysis of 42 studies in 29 countries. European Journal of Public Health. 2011; 10: 1093-7.

7) Hamid O, Shoukry $T$ and Shehata W. Prevalence and pattern of hearing loss in house - held national survey in Egypt. EJENTAS Egyprion Journal, 2010; 11:12-6.

8) Shemesh R. Hearing Impairment: Definitions, Assessment and Management. International encyclopedia of rehabilitation.Research Information and Exchange (CIRRIE). 2010

9) Lawless J. Hypertension update and cardiovascular risk reduction in physically active individuals and athletes. Physician and Sports medicine, 2010; 38: 11-20. doi: 10.3810/psm.2010.04.1757, PMid: 20424397

10) Cruickshanks K. J, Wiley T. L, Tweed T, Klein B, Klein R, Mares-Perlman J and Nondahl, D. Prevalence of hearing loss in older adults in Beaver DamWisconsin: The epidemiology of hearing loss study. American Journal of Epidemiology, 1998; 148:879-86. doi: 10.1093/oxfordjournals.aje.a009713

11) Kros C, Evans M. Tuning in to cochlear hair cells. Journal of Physiology, 2006; 576(1): 7-9. doi: 10.1113/jphysiol.2006.118935, PMid: 16916901, PMCid: PMC1995649

12) Schuknecht, H. Gacek, M. Cochlear pathology in presbycusis. Annals of Otology, Rhinology and Laryngology, 1993; 102:1-16. PMid: 8420477

13) Torre P, Cruickshanks K. J, Klein, B, Klein R, and Nondahl D. The association between cardiovascular disease and cochlear function in older adults. Journal of Speech, Language and Hearing Research, 2005; 48: 473-81. doi: 10.1044/1092-4388(2005/032)

14) Nakashima, T, Naganawa S, Sone M, Tominaga M, Hayashi H, Yamamoto H, et al. Disorders of cochlear blood flow. Brain ResearchReview, 2003; 43(1): 17-28. doi: 10.1016/s0165-0173(03)00189-9

15) Dai P, Jiang Sand Gu R. Cochlear hypoxia and mtDNA deletion: Possible correlated factors to cause presbycusis. Zhonghua Yi Xue Za Zhi, 2000; 80(12): 897-900.

16) Wolfgang M Franz O J Muller H A and Katus. Cardiomyopathies: from genetics to the prospect of treatment. The Lancet, 2001; 8:1616-1627. Doi: 10.1016/s0140-6736(01)06657-0

17) Mohiddin SA, Ahmed ZM, Griffith AJ et al. Novel association of hypertrophic cardiomyopathy, sensorineural deafness, and a mutation in unconventional myosin VI (MYO6). J Med Genet; 41:309-14. doi: 10.1136/jmg.2003.011973, PMID: 15060111, PMCid: PMC1735721

18) Sylvius N,F Tesson C, Gayet P, Charron et al. A New Locus for Autosomal Dominant Dilated Cardiomyopathy Identified on Chromosome 6q12-q16. AJHG, 2001; 241-6. doi: 10.1086/316929

19) Grunig E, Tasman JA, Kucherer H, Franz W, Kubler W, Katus HA. Frequency and phenotypes of familial dilated cardiomyopathy. J.AM.Coll.Cardiol, 1998; 31:186-194. doi: 10.1016/S0735-1097(97)00434-8

20) Schonberger J, Levy H .Gruning E, Sangwatanarj S et al. Dilated cardiomyopathy and sensorineural hearing loss, A heritable syndrome that maps to 6q23-24. Circulation, 2000; 101:1812-1818. doi: 10.1161/01.CIR.101.15.1812

21) Soliman S, Shehata W and Fatthallah A. Development of Arabic Staggered Spondee Words (SSW). 8th Ain Shams Annual Congress, 1985; 2:1220-46. 
22) Soliman . Speech discrimination audiometry using Arabic Phonetically Balanced Words. Ain Shams Medical Journal, 1976; 27; 2730.

23) Keating $M$ and Sangunetti M. Molecular and cellular mechanisms of cardiac arrhythmias. cell (Elsevier), 2001; 104:569-580. doi: 10.1016/s0092-8674(01)00243-4

24) Mayosi B. Cardiomyopathies MOGESs a standardized classification of cardiomyopathies. Nature Reviews cardiology, 2014; 11;134-5. doi: 10.1038/nrcardio.2013.219, PMid: 24419255

25) Arbustini E, Narala N, Dec GW, et al. The MOGE(S) classification for a phenotype genotype nomenclature of cardiomyopathy: endorsed by the World Heart Federation. JAM, Coll, Cardiol, 2013; 62:2046-2072. doi: 10.1016/j.jacc.2013.08.1644, PMid: 24263073

26) Robinette $M$ and Cevette $M$. Case history, integrating audiometric results, and clinical decision analysis. In Katz J., Burkard R., and Medwetsky L. (Eds.), Clinical Audiology, Lippincott and Wikins, United States of America, 2002; ch.10; 142-56.

27) Dobie R. Prevention of noise induced hearing loss. Arch Otolaryngol Head and Neck Surg, 1995; $121: 385-$ 91. doi: 10.1001/archotol.1995.01890040011002

28) Schonberger J, Wang L, Shin JT et al. Mutation in the transcriptional coactivator EYA4 causes dilated cardiomyopathy and sensorineural hearing loss. Nat Genet, 2005; 37:418-22. doi: 10.1038/ng1527, PMid: 15735644

29) Drici M ,Arrighi I, Chouabe C, Mann JR, Lazdunski M,Romey Gand Barhanin J. Involvement of ISKassociated $\mathrm{K}$ channel in heart rate control of repolarization in a murine engineered model of Jervell and Lange -Nielsen syndrome. Circ-Res, 1998; 93:95-102. doi: 10.1161/01.RES.83.1.95

30) Vetter DE, Mann JR, Wangemann P, Liu J, McLaughlin KJ et al. Inner ear defects induced by null mutation of the isk gene. Neuron, 1996; 17:1251-64. doi: 10.1016/S0896-6273(00)80255-X

31) Naviaux R. Mitochondrial DNA disorders. Eur J pediatric, 2000; 159(3):219:226. doi: 10.1007/p100014407

32) Edmonds JL et al. The otolaryngological manifestation of mitochondrial disease and the risk of neurodegeneration With infection. Arch Otolaryngol HNS, 2002; 128: 355-62. doi: 10.1001/archotol.128.4.355

33) Santorelli FM, Mak SC, El-Schahawi M, Casali C, Shanske S, Baram TZ, Madrid RE and DiMauro S. Maternally inherited cardiomyopathy and hearing loss associated with a novel mutation in the mitochondrial tRNA(Lys) gene (G8363A). Am J Hum. Genet, 1996; 58:933-9. PMid: 8651277, PMCid: PMC1914622

34) Sue CM et al. Cochlear origin of hearing loss in MEALAS syndrome. Ann Nearol, 1998; 43:35-59.

35) Gaskill S. A and Brown A. M. The behavior of the acoustic distortion product, 2f1- f2, from the human ear and its relation to auditory sensitivity. Journal of Acoustical Society of America, 1990; 93:205072060. doi: $10.1121 / 1.399732$

36) Solkani T. A study on the prevalence of hearing loss in adults presenting with cardiovascular disease un published thesis University of Witwatersrand. 2012 